\title{
Risk of breast cancer in patients on long-acting insulin analogues in comparison with those on human insulin
}

\author{
K. Kostev
}

Received: 26 December 2011 / Accepted: 9 January 2012 /Published online: 19 February 2012

(C) Springer-Verlag 2012

Keywords Breast cancer - Detemir. Glargine - IMS disease analyzer · Insulin $\cdot \mathrm{NPH}$

To the Editor: In the epidemiological study of Ruiter et al. [1], the association between insulin glargine (A21Gly, B31Arg, B32Arg human insulin), and other insulin analogues, and cancer was analysed based on data from community pharmacies individually linked to hospital discharge records. The use of insulin glargine was associated with a higher risk of breast cancer in comparison with human insulin. I have performed a similar study based on longitudinal data from a large database in Germany (IMS Disease Analyzer Germany) [2], including demographic information, diagnoses, therapies and laboratory values (for example, $\mathrm{HbA}_{1 \mathrm{c}}$ ), from more than 20 million patients in 2,400 primary care practices in 2000-2011. The risk of breast cancer in women with type 2 diabetes in Germany was investigated.

There were 9,222 female diabetes patients given their first prescription for insulin in 2000-2011 in 820 primary care practices: 4,727 patients with insulin glargine (mean age \pm SD $69.8 \pm 11.3$ years), 789 with insulin detemir (B29Lys( $\varepsilon$-tetradecanoyl), desB30 human insulin) (mean age \pm SD $66.2 \pm 11.5$ years) and 4,206 with NPH insulin (mean age \pm SD $66.5 \pm 10.8$ years). The time from

\section{K. Kostev ( $\bowtie)$}

IMS Health, Centre of Excellence Patient Data,

Darmstädter Landstrasse 108,

60598 Frankfurt am Main, Germany

e-mail:kkostev@de.imshealth.com start of insulin therapy to the first primary care diagnosis of breast cancer was compared between insulin glargine, detemir and NPH in a Cox model adjusting for age, sex, private insurance status, urban location of a practice, region and $\mathrm{HbA}_{1 \mathrm{c}}$ level. Furthermore, a revised version of the Charlson comorbidity index was used as generic marker of comorbidity [3]. The Cox proportional hazard model also included cumulative duration of drug use as a time-varying determinant.

In this study, adjusted hazard ratios for breast cancer were $0.93(95 \%$ CI $0.68,1.27)$ for insulin glargine and 1.17 (95\% CI 0.66, 2.06) for detemir, compared with NPH. The risk for breast cancer was significantly higher for older patients $(p<0.05)$.

Our primary care data do not support the findings of Ruiter et al. [1] regarding the relative risk of breast cancer in women treated with insulin glargine compared with NPH. This might be explained by differences between the two patient databases, but argues against the likelihood of a true increase in breast cancer risk with glargine. Further studies in other countries on the association between insulin and cancer risk are needed to establish whether the use of insulin glargine is associated with a higher risk of breast cancer in comparison with human insulin.

Duality of interest The author declares that there is no duality of interest associated with this manuscript.

Contribution statement KK was responsible for the conception and design, and analysis and interpretation of data; drafting the article and revising it critically for important intellectual content; and giving final approval of the version to be published. 


\section{References}

1. Ruiter R, Visser LE, van Herk-Sukel PP M et al (2012) Risk of cancer in patients on insulin glargine and other insulin analogues in comparison with those on human insulin: results from a large population-based follow-up study. Diabetologia 55:51-62
2. Becher H, Kostev K, Schröder-Bernhardi D (2009) Validity and representativeness of the "Disease Analyzer" patient database for use in pharmacoepidemiological and pharmacoeconomic studies. Int J Clin Pharmacol Ther 47:617-626

3. Quan H, Sundararajan V, Halfon P et al (2005) Coding algorithms for defining comorbidities in ICD-9-CM and ICD-10 administrative data. Med Care 43:1130-1139 